\section{TECHNICAL TIPS}

\section{A simple technique to avoid blockage of the suction system in laparoscopic procedures}

Hany Balamoun, Samer Doughan, Mansoor Akhtar

Department of General Surgery, Queen Elizabeth The Queen

Mother Hospital, Margate, UK

\section{CORRESPONDENCE TO}

Hany Balamoun, E: hanyarmia80@gmail.com

A tonsil swab is inserted through a $10-12 \mathrm{~mm}$ port and the suction tip is placed over the swab to get rid of any fluid. In such a technique, the swab will act as a barrier and the fluid can be sucked in all areas of the abdominal cavity without allowing omentum or fat to cause blockage of the suction tip (Fig 1)

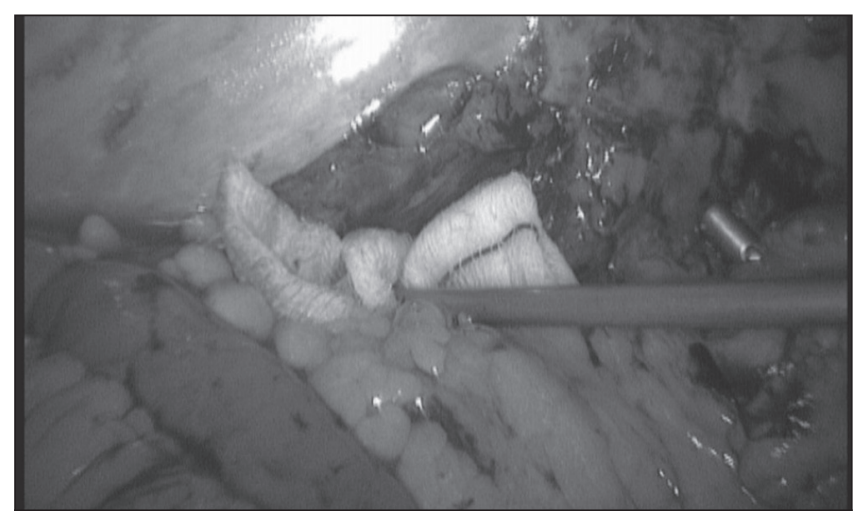

Figure 1 The area is dry after suction through the tonsil swab.

\section{A new technique for hamstring donor site blockade in anterior cruciate ligament recon- struction}

\section{JS Logan, RR Elliot, AJ Wilson}

Basingstoke and North Hampshire NHS Foundation Trust, Basingstoke, UK

\section{CORRESPONDENCE TO}

James Logan, E: james.logan@doctors.net.uk

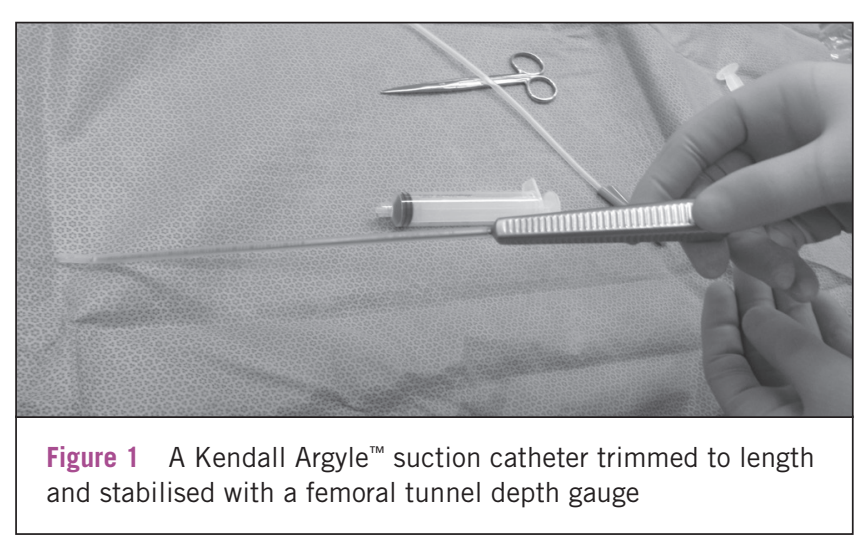

Harvesting of the hamstrings for anterior cruciate ligament reconstruction can be a significant cause of postoperative pain along the course of the stripped tendons. This can be attenuated via direct infusion of local anaesthesia. ${ }^{1}$ We have devised a technique for administering local anaesthetic along the hamstring graft harvest tract.

A Kendall Argyle ${ }^{\mathrm{TM}}$ (Covidien LP, Gosport, UK) suction catheter is trimmed to length and stabilised with a femoral tunnel depth gauge (Fig 1). This device is inserted along the course of the harvested hamstring tendons; the depth gauge is removed. We inject $62.5 \mathrm{mg}$ of bupivacaine made up to a total volume of $50 \mathrm{ml}$ with normal saline $0.9 \%$ as the catheter is withdrawn. This is given as a single bolus with no subsequent top-up.

\section{Reference}

1. Bushnell BD, Sakryd G, Noonan TJ. Hamstring donor-site block: evaluation of pain control after anterior cruciate ligament reconstruction. Arthroscopy 2010; 26: 894-900.

\section{Lagging the Synthes ${ }^{\circledR}$ locking compression proximal femoral plate $4.5 / 5.0$ to the proximal femur}

AD Carrothers, RG Turner

Princess Royal Hospital, Telford, UK

CORRESPONDENCE TO

Andrew Carrothers, E: carrothersandrew@hotmail.com

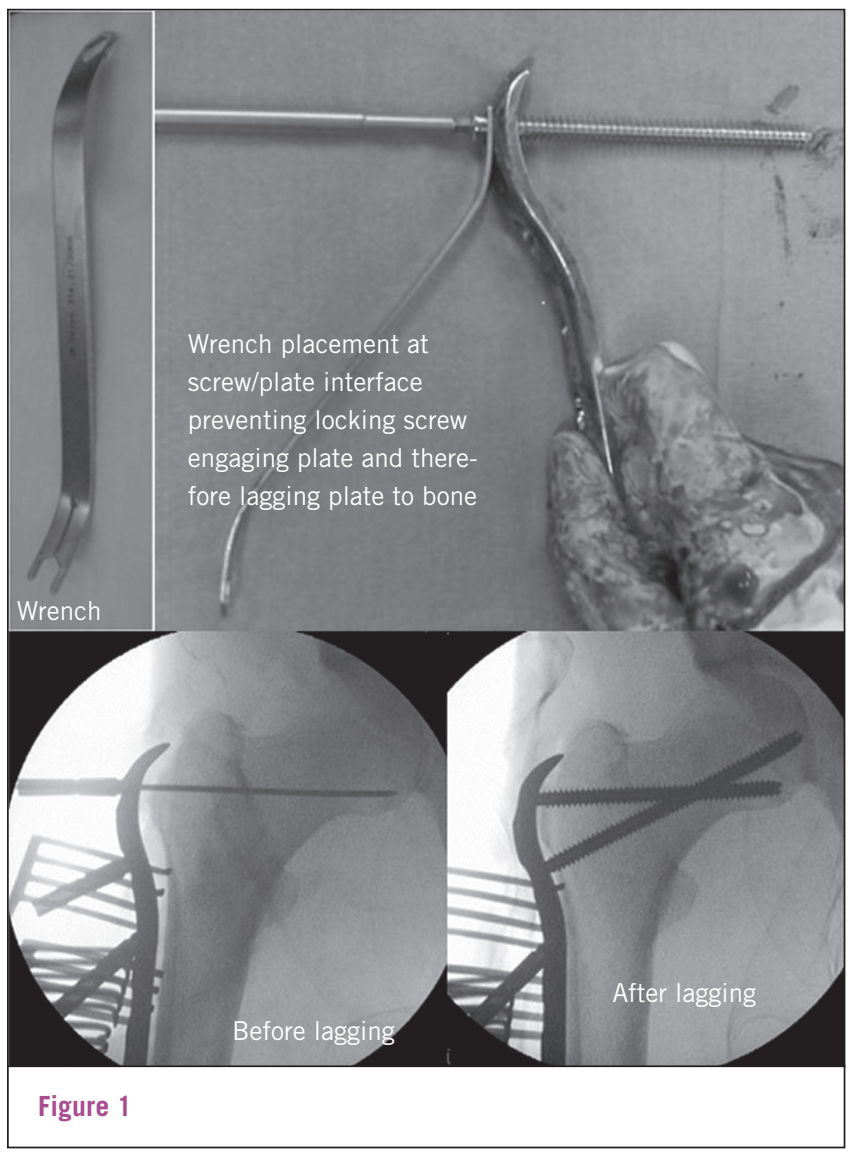

